\title{
Knowledge Translation Platform Increasing Use of Research Evidence in Physical Activity Policy Making - A Case Study in Finland
}

\author{
Riitta-Maija Hämäläinen ${ }^{1}$ \\ ${ }^{1}$ National Institute for Welfare and Health, Helsinki, Finland \\ Correspondence: Riitta-Maija Hämäläinen, National Institute for Welfare and Health, Mannerheimintie 166, \\ FI-00271 Helsinki, Finland. Tel: 358-29-524-7464.
}

Received: May 16, 2017 Accepted: July 3, 2017 Online Published: July 17, 2017

doi:10.5539/gjhs.v9n9p126 URL: https://doi.org/10.5539/gjhs.v9n9p126

\begin{abstract}
Background: Knowledge Translation Platform (KTP) in partnerships between policymakers, stakeholders, and researchers was established in order to enhance evidence-informed policymaking on physical activity. The article aims to give answers to specific questions, such as what were the main knowledge translation tools to improve access to research evidence in physical activity policy in Finland; which factors facilitated the improvements in use of research evidence, and what kind of procedures were implemented to improve the use of research evidence in policy making.

Methods: The study triangulated qualitative data from documents, reviews and observations of meetings between 2012 and 2013. Purposive sampling of meeting documents was used and data was analysed using a thematic content analysis of documents.

Results: KTP contributed to an increased awareness of the importance of the use of research evidence in physical activity policymaking, and strengthened relationships between policymakers, stakeholders and researchers. Support from policymakers and professionals as well as a window of opportunity facilitated KTP activities. Based on the KTP experience, institutionalization within the government could help to keep the use of research evidence high on the agenda.

Conclusions: The case study provided unique insights into what counts for developing use of research evidence in policymaking. The expectations of the public policy were to give a larger role to evidence-informed policymaking, but expectations conflicted between the interests of various stakeholders. The establishment of KTP was a promising development in supporting the use of research evidence in physical activity policymaking. Real-time lesson drawing from the experiences of KTP can support improvements in the functioning of KTP in the short term, while making the case for sustaining their work in the long term.
\end{abstract}

Keywords: knowledge translation, knowledge translation platform, physical activity, policymaking, research evidence

\section{List of Abbreviations}

KE knowledge exchange theory

KT knowledge translation

KTP knowledge translation platform

MEC Ministry of Education and Culture

\section{Background}

As defined by Lavis, Boyko, Oxman, Lewin, \& Fretheim (2009) evidence-informed policy making refers to the use of the best available data and research evidence at the time of informing policymakers. The use or non-use of research evidence in policy making is an issue of growing interests and concern among both academic researchers and policymakers (Hunter, 2009; European Commission, 2010). Several reports and papers conclude with calls for a better translation of research into practice and policy (Giles-Corti, Sallis, Sugiyama, Frank, Lowe, \& Owen, 2015; Haskell, Blair, \& Hill, 2009; Ojajärvi, Pyykkönen, \& Valtonen, 2013; Valtioneuvoston kanslia, 2011; Ilmakunnas, 
Junka, \& Uusitalo, 2008).

Knowledge Translation (KT) has appeared as one of the methods for closing the gap between knowledge and practice. Straus, Tetroe, \& Graham (2009) defined KT as 'a dynamic and iterative process that includes the synthesis, dissemination, exchange and ethically sound application of knowledge to improve health, provide more effective health services and products, and strengthen the health services'.

Lavis, Robertson, Woodside, McLeod, Abelson, \& Knowledge Transfer Research Group (2003) proposed an integrated KT model for policy making. That means creation of a Knowledge Translation Platform (KTP) to build linkages and exchange efforts across health systems. KTP works to align the research efforts of researchers with the need of policymakers and influencing policy dialogue with research evidence.

Knowledge Exchange (KE) has been used for closing the gaps between knowledge to practice (Straus et al 2009). In addition, $\mathrm{KE}$ theory is a collaborative problem-solving process among public health practitioners, researchers, and decision-makers, which takes place through linkages and exchanges. It results in a mutual learning through the process of planning, producing, disseminating, and applying existing or new research to decision-making (Ontario Public Health Standards, 2008). KE is about getting the right information to the right people in the right format at the right time by KTP.

This study sought to gain a better understanding of knowledge translation processes, and aims to describe KT tools towards the promotion of evidence-informed policy making by taking physical activity as a case. It examines the process of increasing the use of research evidence on the physical activity promotion agenda in Finland through the lenses of KT and applying that theoretical model to the practical policy making process applied from the backward design of knowledge translation by El-Jardali \& Fadlallah, 2015. The use of research evidence in public health and specifically in the promotion of physical activity is claimed to be weak (Pratt, Perez, Goenka, Brownson, Bauman, Sarmiento, \& Hallal, 2015). However, the health benefits of physical activity are well-known (Lee, Shiroma, Lobelo, Puska, Blair, \& Katzmarzyk, 2012; Proper, Singh, van Mechelen, \& Chinapaw, 2011), but the challenges remain in the methods used to assemble research evidence and the political context in which that research evidence is deployed or not deployed in order to inform policy making and practice. The article aims to give answers to specific questions, such as what were the main KT tools established to improve access to research evidence in physical activity policy in the Ministry of Education and Culture; which context factors facilitated or hindered the improvements of access to research evidence for physical activity policy making, and what kind of processes with KT tools were implemented to improve the use of research evidence in policy making.

\section{Methods}

In this study, the working group at the Ministry of Education and Culture (MEC) functioned as a knowledge translation platform (KTP): an intermediary to build up capacity to increase the use of research evidence in policy making for physical activity. KTP was formed by MEC, and included the Secretary General of the National Sports Council, senior planning officer of MEC and a contracted expert from the Finnish Society for Sport Sciences, various representatives of institutes, and professionals to improve access to research evidence in policy making in the MEC.

The structured reflection of the work on KTP drew on multiple sources of qualitative data, namely: i) documents, reviews, reports, minutes and presentations from the meetings and conference of KTP; and ii) observation of the meetings and conference of KTP (Table 1). A purposive sampling strategy was used (Palinkas, Horwitz, Green, Wisdom, Duan, \& Hoagwood, 2015). Data generated from the meetings was triangulated with the documents, reviews and observation of deliberations to confirm, challenge, and refine emerging themes. The reliability and validity of the data were enhanced through iterative data collection. The study was based on participant-observations by the author, and makes no attempt to present the views of other participants, but highlights that the research evidence in policy making have a meaning and is powerful when used as arguments and that the process is unavoidably social and political. 
Table 1. Collected data, sources, and objectives

\begin{tabular}{lll}
\hline Methods (sample size) & Sources & Objectives \\
\hline $\begin{array}{l}\text { Observation of deliberations in } \\
\text { meetings and conferences ( 8 meetings } \\
\text { and one conference) }\end{array}$ & $\begin{array}{l}\text { Observation of } \\
\text { deliberations at the } \\
\text { meetings and conference }\end{array}$ & $\begin{array}{l}\text { Describe the climate, activities, and lessons } \\
\text { learned, including facilitating factors and } \\
\text { challenges in relation to use of research evidence }\end{array}$ \\
$\begin{array}{l}\text { Analysis of documents and review (1 } \\
\text { report, minutes and consultations) }\end{array}$ & Report of KTP 2013 & $\begin{array}{l}\text { Identify outcomes achieved, and lessons learned, } \\
\text { including facilitating factors and challenges }\end{array}$ \\
$\begin{array}{l}\text { Two research projects providing } \\
\text { research results on the use of research } \\
\text { evidence in policymaking }\end{array}$ & Project reports and articles & $\begin{array}{l}\text { To identify the facilitators and barriers for the use } \\
\text { of research evidence in physical activity policy } \\
\text { making }\end{array}$ \\
\hline
\end{tabular}

Individuals and representatives of associations were purposefully invited into KTP based on their interest to increase the use of research evidence for policymaking.

The overall goal of KTP was to promote the generation and use of research evidence in physical activity policymaking as a mean to improve health e.g. increases physical activity in population. Fifteen members were invited to join KTP. They represented MEC (chair), the National Sports Council (secretary),two professors from the University of Jyväskylä, and one person from each of the following bodies: the Finnish Society of Sport Science, Ministry of Finance, Statistics Finland, Youth Research Society, Regional Authority, Association of Sport Clubs, UKK Institute, enterprise, and the National Institute for Health and Welfare. Six of the participants had researcher training at least at the doctoral level, and gender balance was applied in the working group.

The process of knowledge translation to increase the use of research evidence in physical activity policymaking in a Finnish context used a set of knowledge translation tools for policymaking. The tools were the following: 1) Priority setting for the use of research evidence in policymaking; 2) Development of a working group (e.g. KTP) on 'Improving accessibility for information, knowledge and research evidence for sport and physical activity policymaking'; 3) Research evidence in policymaking from two coinciding research projects; 4) Convening national policy dialogue and evaluation of policy dialogue, and 5) Report of the process of the knowledge translation platform and dissemination of the results to politicians and policymakers. (Figure 1).

KTP pursued the goal to increase use of research evidence by harnessing existing methods and approaches to improve both the quality of research evidence and its uptake in policy making. The backward design of knowledge translation was used as analytical frame for the analysis of tools and process (El-Jardali \& Fadlallah, 2015). Documents and deliberations hold in the meetings and conferences were sampled and prioritised by the author based on their relevance to the work undertaken by KTP. Findings from the observations and analysis of documents were summarized using thematic analysis approach and were then used as an input to review the use of research evidence in physical activity policy making.

\section{Results}

\subsection{Priority Setting for Evidence-Informed Policy Making in Physical Activity}

Interventions to increase use of research evidence in physical activity policy making require processes involving complex mix of factors, such as leadership, changing environments and organizational history and culture. In this kind of complex system of physical activity promotion, the type of evidence that can inform policy making is not reducible to experimental designs or clinical trials as implemented in clinical medicine. Nor can it be assumed that the results communicated by researchers would be accepted without questions as to why, how and in what ways the situation can be transformed.

MEC-is in charge of physical activity policy and has nominated various working groups to improve the use of research evidence in policy making (Opetusministeriö, 2006; Opetus- ja kulttuuriministeriö, 2013). The government of Finland attached priority to evidence-informed policy making (Valtioneuvoston kanslia, 2011). In addition, the Ministry of Finance (Prime Minister's Office, 2013) had established a multi-country research project, 'The government for the future', underlining horizontal policymaking, systematic use of research evidence in policymaking and promoting innovation and building learning capacity.

Therefore, MEC also inaugurated discussion and appointed a working group (e.g. KTP) to facilitate the use of research evidence in policymaking. MEC aimed to get the research community to respond to the needs of the administration to produce research evidence for policymaking on time. The urgent issues were the challenges of 
decreasing physical activity in the population, increasing overweight and impoverished social determinants of health (Kestilä, Mäki-Opas, Kunst, Borodulin, Rahkonen, \& Prättälä, 2014; Roskam, Kunst, VanOyen, Demarest, Klumbiene, Regidor et al., 2010). All these issues required research to generate new understanding of renewal of physical activity policy making and practice.

As a daily task, MEC prepared guidelines and measures to be carried out in the physical activity policy making, decisions and implementation. All these activities required a broad knowledge base and capability of cross-sector thinking and ways of working. The legislative and regulatory control of policies required the development of social justification and research evidence on physical activity. The research evidence needed for the policymaking consisted of basic indicators for physical activity clubs and organisations, development of physical activity in population groups, and anticipating knowledge and information needs for social changes. In addition, the state administration needed data for monitoring and evaluating the impact of policies to design new measures in various topics related to physical activity.

Despite the work done, access to research evidence and follow up information has not been satisfying for policy making in physical activity or for the evaluation of the impacts of decisions (Valtonen \& Ojajärvi, 2013). The challenges between policy making and follow up information has remained around the following three issues: production of research evidence with better quality and impact on policy making; better organised, filed, processed and interpreted research evidence to improve use of research evidence; and the impact of research evidence to the actual physical activity policies (Valtonen \& Ojajärvi, 2013).

The administration of MEC underlined that researchers should produce and disseminate research evidence in practical and accessible ways (Valtonen \& Ojajärvi, 2013). But there was the collision of the two worlds: the academic peer reviewed publications versus research evidence produced for the use of policymakers with an impact. The third issue was how to get busy policymakers and academics to interact and understand each other so that both benefitted in terms of using research evidence in policymaking and researchers identifying new research topics and issues to be funded. Certainly research evidence in policymaking was, if not completely ignored, and then often used inconsistently, discontinuously and disproportionately (Valtonen \& Ojajärvi, 2013).

\subsection{Creation of the Knowledge Translation Platform}

KTP aimed for better accessibility and physical activity information and increased use of research evidence in policymaking. KTP was chaired by the MEC and its Sports and Physical Activity Section during 2012-2013. The receptive climate for the use of research evidence in physical activity policymaking encouraged the participants to develop a priority for KTP in political, administrative and economical contexts. It was also noted that several processes for the increased use of research evidence were undergoing change including reforms of funding for research institutes and universities (Virtanen, Stenvall, \& Rannisto, 2015).

The tasks of KTP established by MEC were exposed to discussion and changes. In KTP the tasks were subsequently defined as to map the present use of research evidence and the level and quality of research evidence used in policymaking. KTP defined the role of stakeholders in policymaking from the point of view of using research evidence. KTP made proposals and suggestions to improve interaction and actions necessary for the further use of research evidence in physical activity policymaking and to renew the current practices and roles of various stakeholders. Finally, KTP discussed the possibilities of improving access to research evidence through information and communication technology.

\subsection{Collected Research Evidence on the Use of Research Evidence for Policymaking to Inform KTP}

Two research projects were conducted in order to understand the use of research evidence in physical activity policymaking. One of the research projects was conducted by media researchers at the University of Helsinki and managed by the Society of Sport Science. The results indicated that the main problems were related to the separation of the institutes in the field of research and the lack of public debate and interaction between different institutes and actors (Valtonen \& Ojajärvi, 2013). The fragmentation of production of research evidence, strong scientific and disciplinary differences and disputes and competition between organizations hindered cooperation and use of research evidence for physical activity policymaking. Therefore, the structures and consolidated networks of interaction on annual basis was recommended to share information, discuss issues and topics and increase interaction and communications to bring together policymakers, researchers, and other professionals in substance-specific items (Valtonen \& Ojajärvi, 2013).

In addition, the study informed that there was a need for a clarification of the roles of producers of research evidence, translators and users of research evidence and structural connections between different stakeholders. However, in practice, the actors had several roles in relation to knowledge: every actor worked in at least two, if 
not all three of the roles as producer, broker and beneficiary in promoting research evidence into policymaking (Valtonen \& Ojajärvi, 2013).

The study conducted interviews in which many expressed their distrust in relation to media and its use of research evidence in public debates (Valtonen \& Ojajärvi, 2013). The role of the media as simplifying and distributing the research evidence was not appreciated and understood for the benefit of researchers or research funding. Further on the interviewees considered that media and public discussion was held to be no more than a channel for citizens, not for the creation of public opinion or support for the use of research evidence for physical activity policy making. Among the interviewees there was a strong reluctance to discuss research evidence on physical activity in the media even if the media was considered to be a key producer and broker of research evidence for policymaking.

The second project and its findings supported KTP on the use of research evidence in physical activity policies from the international perspective (REsearch into POlicy to enhance Physical Activity REPOPA). The goal of the research was to explain the use of the research evidence and other evidence in policymaking of physical activity at various administrative levels in six European Union member states. Part of the study analysed policy actions in the field of five Finnish physical activity policies.

The results of REPOPA showed that policymaking at all levels of the Government arose from the variety of processes with a blend of different data, strategic documents and resources. In addition, the policymaking occureds in the streams and chains of decisions and public discussion in media influence on policies and policymaking. On the basis of access to research evidence, the interviewed policymakers underlined the access to research evidence as necessity for the sake of the credibility of the policy measures. However, the initiative for the policy measures was often the political will complemented by the evidence from the management and organization information, experience-based information, information from physical activity culture in general and the exploitation of existing good practice (Hämäläinen \& Villa, 2014). REPOPA showed that research evidence was on the background of physical activity policies, but the systematic breakdown of the studies was not included due to the nature of the policymaking for the development of the current processes.

According to REPOPA study physical activity policies were usually prepared in the working groups including expertise input. The experiences of the experts involved filtered research evidence and interpreted research evidence during the process of policymaking, but it was impossible to trace to certain research results (Hämäläinen \& Villa, 2014). On the basis of the results in REPOPA the policymaking used research evidence, empirical knowledge, media related information and political information. The research data used included reports, studies, statistics, and population based surveys. Experience-based evidence was collected from the policy networks, meetings and appointments, best practices, projects and learning from successes and failures in physical activity implementation. In particular, the policy measures were influenced by the internet and media-set trends as well as a variety of newsletters and publications, in particular at regional and local level policymaking. In general, the research evidence was used in the justification parts of policies (Hämäläinen \& Villa, 2014).

\subsection{Convening National Policy Dialogue}

As the use of research evidence on physical activity and access to research evidence is more than to collect, store or disseminate research evidence for policymaking, the focus of KTP moved from the research-practice nexus into applied use of research evidence in policy making. Applied use of research evidence required enhanced cooperation, interaction and networking between researchers, practitioners and policymakers. As the studies showed, the physical activity sector missed the opportunities to discuss physical activity policies with researchers, practitioners and policymakers on issues such as how research evidence could improve the present situation, the future scenarios and foresights for physical activity in society, and what direction society in general should take.

Therefore KTP invited about 50 participants from different stakeholders groups and 26 representatives of various stakeholders participated into the open consultation on the use of research evidence in policymaking and how to enhance the processes to get research evidence into policymaking.

The use of research evidence in practice was collected from stakeholders by a semi-structured online survey. Responders represented municipalities, organisations and professionals. In addition, hearing of stakeholders was organised with discussion on the results of the online survey. The semi-structured online survey focused on the following issues:

1) Describing the level and quality of physical activity policymaking and use of research evidence (weaknesses and strengths);

2) Describing role in producing and disseminating research evidence for physical activity in policymaking; 
3) Changing roles of stakeholders in order to increase access to research evidence in policymaking;

4) Strengthening proposals for the use of research evidence in producing disseminating and sharing and using research evidence (decision making, promotion of physical activity, etc.);

5) Increasing the most useful sources and systems for physical activity and use of research evidence in policymaking;

6) Evaluating the need for an IT system/portal to collect research evidence, evaluation and follow up information;

7) Describing other processes from other sectors to promote the access to research evidence.

All the answers were combined into one document. In the stakeholders meeting, responses to each question were presented by the invited discussant and discussed further with all other stakeholders.

Responses to the semi-structured online survey underlined the need to manage the use of research evidence and produce new knowledge, which is easily available, organized, combined and retrieved. In addition the responses emphasized that the experts need more ability to apply their knowledge in a variety of problem-solving situations in a new way and to operate in an open, networking based environment to acquire and use research evidence in policymaking. Further on professionals and experts need more training in the use of research evidence in policymaking and implementation.

The stakeholders also discussed on the data system and its architecture for the collection of research evidence in order to deal with the vast number of sources. According to the stakeholders the aims should be to improve the effectiveness of the strategic and social support for the research evidence in physical activity policymaking to achieve the objectives of physical activity policy.

The discussion with stakeholders brought up relatively strong scientific borders of disciplines and added to the dialogue a debate on the contribution of each discipline to research evidence in policymaking: from essential research evidence to securing the missing research evidence. The discussion realised, that there was lack of good practices in the use of research evidence in physical activity policymaking and, therefore, the policymaking process and use of research evidence in its various phases needed to be described in the Finnish context.

\subsection{Report of KTP Process and Dissemination of the Results to Politicians and Policymakers}

The mandate of KTP was to make a proposal on the development of the role of various actors and how to increase the use of research evidence. KTP indicated that the responsibility of specific roles in producing, interpreting and disseminating should be clarified. For the increased use of research evidence in physical activity policymaking, the division of work and the perception of the roles in the production and dissemination of research evidence for policymaking should be made clear. The resources and how to organize the production and dissemination should be agreed so as to avoid duplication of work. The coordination of the production of research evidence and intermediaries for the interpretation of research evidence needed to be strengthening. The roles of the researchers and use of research evidence in policymaking should be sufficiently known by all stakeholders.

The report of the KTP was delivered to MEC for further action. The KTP considered that research evidence in physical activity was dispersed, but the decision-making needed often punctual delivery at the right time. Academic research reporting practices did not support the use of active transmission of research evidence for decision making. Therefore there was a need for different actors to increase dialogue between the disciplines. KTP encouraged the use of research evidence in policymaking and in the preparation of a systematic decision-making at the various stages of the process. This required change of culture and needed measures from MEC to sharpen and control policy to make research communities produce research evidence for the purpose of policymaking. In addition the National Sports Council was asked to identify the various players in the physical activity policy and their key roles. Further on the researchers were asked to produce high-quality, reliable and relevant scientific research. The existing scientists and science communities should open databases to other researchers. Moreover increased communication, networking and exchange between research topics, researchers, practitioners, decision makers and the scientific communities were recommended. The renewed interaction in the preparatory phase of the planning and policy making should ensure the broad consensus on the use of research evidence.

\section{Discussion}

The application of KT tools to generate improved evidence-informed policymaking was an interesting experiment in the Finnish context. This process served as a demonstration of stakeholders participation and consultation in policymaking.

In this case study a window of opportunity emerged for the enhancement of use of research evidence in physical 
activity policymaking. MEC took the opportunity and invited professionals and other stakeholders for KTP. By establishing priorities, KTP, a policy dialogue and research projects, MEC was able to inform policy makers. The dialogue brought together many representatives, which were dependent or affected by future decisions related to use of research evidence in physical activity policy making. In the policy dialogue diverse participants were able to share problems and its elements in the use of research evidence in physical activity policy making and discuss the challenges between different types of research evidence.

The results of this study support the observations on gaps by Hawkes et al. (2015) in understanding the mechanisms influencing the use of research evidence on policymaking processes and how policymakers can be encouraged to use research evidence. Hardly any resources were directed at capacity development to promote greater use of research evidence in policy makers in this study either.

The stakeholders had various roles in policymaking. That meant that the role of each participant varied from knowledge broker to researchers and others, such as facilitator, transferring knowledge for policymaking, transforming knowledge, knowledge manager (like librarian), linkage agent (like towards researchers), capacity builder (training and education institutes) or participant as representative of certain project, programme, or institute to defend a stand, proposal or similar. The role of participants in a knowledge platform can be constantly changing depending on topics, issues or concerns under discussions and decisions for a policy. Therefore the role of participant in KTP or consultation varied and provided multitude of possibilities for interpretations on each interventions.

Hallsworth (2011) mentioned that both political aims and desires contribute to policymaking and political climate. Political appetite for using research evidence might be the greatest driver for the capacity strengthening (Hallsworth, 2011). In this study the driving force to increase use of research evidence in policymaking in Finnish physical activity policy was both political desire and administrative needs.

The study also confirmed the conclusions of Hawkes et al. (2015) that policymaking processes should be strengthened through organizational capacity building and through data depositories, upgrading of institutional infrastructures and variety of multimedia/social media messages. To increase the capacity to have access to research evidence. In this study, increased interactions between policymakers and researchers were considered to be vital to increase the uptake of research evidence also.

Based on Clark \& Weale (2012) the nonexistence of institutional norms and rules around the use of evidence, rise a concern that decisions on health policy are more subject to value-based decision making rather than evidence informed processes or even more provincial norms and interest of decision makers (Buse, Mays, \& Walt, 2012). Therefore KTP provided the first ever experiment on developing dialogues and improved use of research evidence in physical activity policymaking.

According to Hawkes et al. (2015) the capacity for the access, analysis and interpretation of research evidence lay outside of policymakers and mostly within specialized agencies. Stakeholders have different roles in research evidence, such as identifying information and research evidence, redistribution of research knowledge and rescaling and transforming knowledge to policymakers or other people. In KTP stakeholders of various institutes performed activities in relation to the use of research evidence. Stakeholders articulated on research evidence, communicated research evidence, identified and mediated research evidence, educated and created concepts in common language rather than in research language. The important issue was how to translate the research evidence for policymakers and identify the interesting and appealing approaches to each of policymaker and make arguments at the right time and in the right place to the right policymakers. The gaps and links between research, policymaking and practice nexuses became important and crucial to enhance the use of research evidence in KTP and the overall process.

Findings from the study on knowledge platform work are congruent with those previously reported by policymakers, stakeholders, and researchers on evidence-informed policymaking (El-Jardali, Lavis, Ataya, Jamal, Ammar, \& Raouf, 2012; Wallace, Byrne, \& Clarke, 2012; LaRocca, Yost, Dobbins, Ciliska, \& Butt, 2012; El-Jardali, Jamal, Ataya, Jaafar, Raouf, Matta, \& et al. 2011; Wallace, Nwosu, \&Clarke, 2012; Scott, Albrecht, O’Leary, Ball, Hartling, Hofmeyer, \& et al. 2012; Barwick, Schachter, Bennett, McGowan, Ly, Wilson, \& et al. 2012). Gaps in research production in relation to priorities of MEC, as well as a lack of skills among research users to acquire, assess, adapt, and use research evidence, were reported to hinder the use of research evidence in policymaking. Similar results have been reported by El-Jardali et al. (2011). There is little empirical evidence on effective KT approaches and how KT strategies can be tailored for different contexts and disciplines (Wallace, Nwosu, \& Clarke, 2012; Scott et al., 2012; Barwick et al., 2012). 
This study supports the positive views on deliberative dialogues, where very favourably and strong intentions to act are presented and learned in dialogues (Moat, Lavis, Clancy, El-Jardali, \& Pantoja 2014). Furthermore, making changes to the existing institutional structures and incentives of researchers in terms of research funding and use of research in policymaking, have suggested as strategies to encourage policymakers to use of research evidence in policymaking initiatives. Researcher and policymakers has been described as living in different worlds and often researchers tend to think that merely publishing research results in the scientific community would be sufficient for the take up of the findings and recommendations in policies (Brownson, Royer, Ewing, \& McBride, 2005). More and more funding agencies demand more effective ways of dissemination and application of research findings; researchers are partially responding to this shift, recognizing that the completing the research is not the end to the process but, rather the start of applying and implementation of research results (Smits \& Denis, 2014). This was particularly mentioned in KTP and stakeholder dialogue in the Finnish context.

Better science communication is one of the keys to resolving this kind of dilemma. Better communications with the public and policymakers can help scientists send clearer messages in relation to the accomplishments, promises, and uncertainties of their work (Pratt et al. 2015; Malta \& Barbosa da Silva, 2012). Better communication between researchers, policy makers and media was a key finding of KTP and dialogue with stakeholders. This addressed the scientists' role in enhancing and advising on physical activity services, facilities and opportunities. The result might bring productive dialogues about science and the political, social and moral implications.

Interactive processes are defined as knowledge translation in terms of exchanges, synthesis, dialogue and interaction between researchers and user of research findings (Canadian Institutes of Health Research, 2004). However, the challenges and problems in the societies are multiple and complex. This requires two-way communication and involvement from researchers with their users of research findings e.g. therefore, users should have an influence on research questions also. Therefore citizen participation in policymaking should be encouraged.

\section{Conclusions}

While the study is descriptive by nature, the case study revealed complexity in policymaking and in the construction of tools for increased use of research evidence in policymaking. The possibility of applying a more robust knowledge translation approach to tackle the physical activity and use of research evidence in policymaking could prove to be a valuable mean to bring research evidence into policymaking (Figure 1).

In Finland, a window of opportunity to enhance the use of research evidence in policymaking was identified due to the renewal of physical activity policy and reviewing law concerning physical activity. MEC and the Finnish Society of Sport Sciences provided the support and leadership for the attempt to increase the use of research evidence in policymaking.

The process and policy dialogue with stakeholders helped inform policymakers at the governmental level. The policy dialogue, which was informed by a pre-circulated questionnaire helped trigger and support multiple actions by policymakers directly related to the integration of research evidence of physical activity into policymaking, as well as actions aimed at strengthening other aspects of physical activity. Participants pointed out that the policy dialogue was an important opportunity for diverse groups of people to deliberate about the problems and its elements. Policy dialogue brought together participants, who could be involved in or affected by future decisions related to the use of research evidence in physical activity policy making (See Figure 1).

Framing of the problems of the use of research evidence in policymaking seemed to be critical. The key informants in KTP and policy dialogue helped in refining the problems. The policy dialogue also served to validate the research evidence synthesised in the policymaking process, whereby the policy to address the problems was mostly supported by the research evidence, but also by the results of policy dialogue. The choices made by the participants to pursue issues might not have been influenced only by the strength of the research evidence supporting it, but also by the feasibility of application in Finland. The policy dialogue was instrumental in contextualising the challenges of the use of research evidence in policymaking, especially from the production side of research evidence (See Figure 1). This further emphasised the importance of taking the local context into consideration when discussing use of research evidence and deciding on options to pursue. The studies have shown that the uptake of evidence by policymakers and its usefulness in supporting evidence-informed physical activity policies is influenced by contextual factors, such as institutions, interests and values in the local context (Moat, Lavis, \& Abelson, 2013).

Related studies have shown that follow-up activities can help continue building the capacity of stakeholders to add the use of research evidence in policymaking. Such activities include dissemination of dialogue summaries, 
providing customised debriefings, or offering providing newly published systematic reviews (Lavis et al. 2009; Boyko, Lavis, Abelson, Dobbins, \& Carter, 2012). However there is not strong evidence that this would be happening in physical activity policy implementation in Finland.

Framework for increased use of research evidence in HEPA policy making

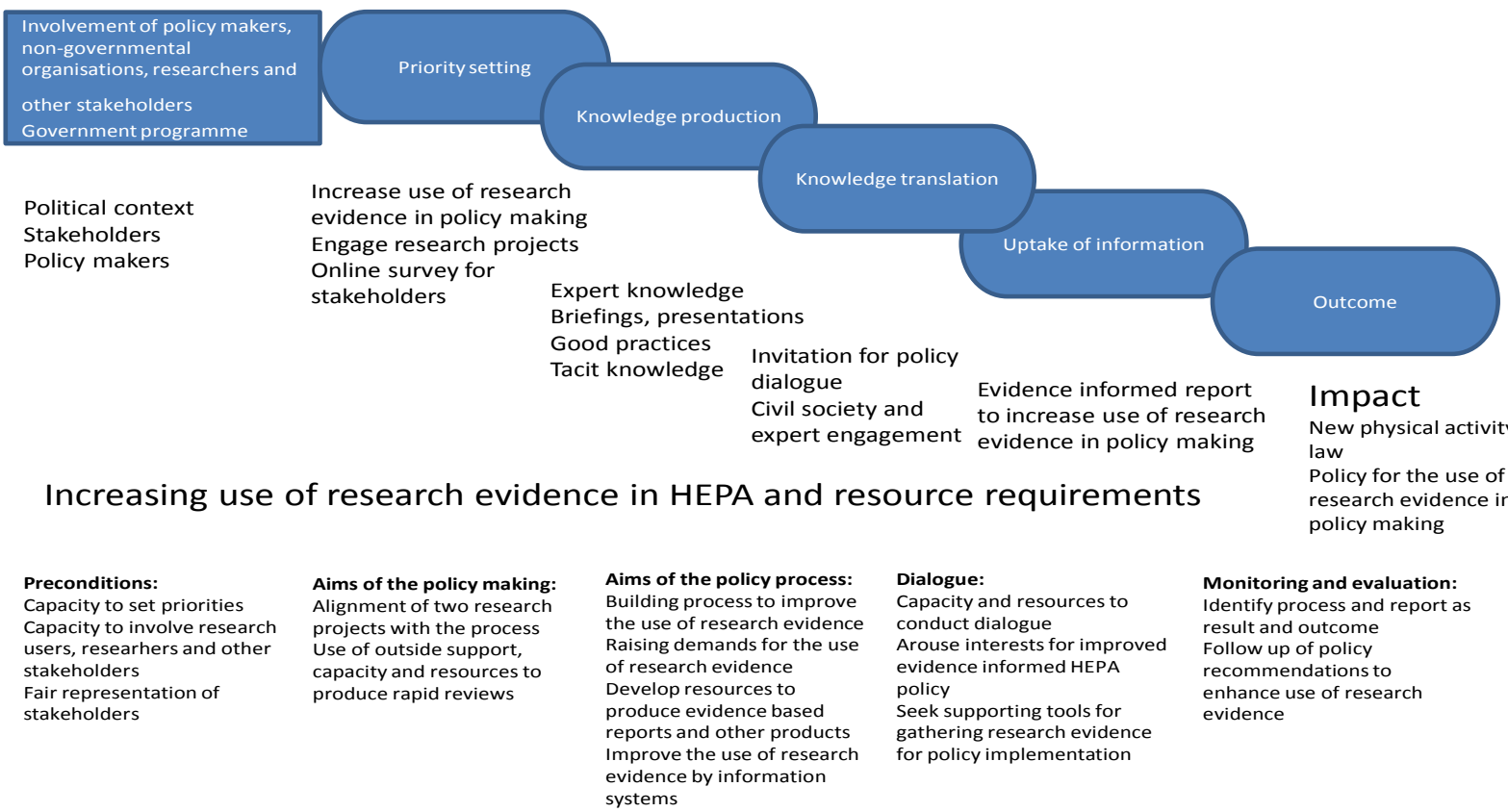

Figure 1. Framework for increased use of research evidence in HEPA policy making

\section{Ethics}

The national research groups collected ethical clearance documents from the ethical committees in various countries, also in Finland. A package was submitted to the European Commission (Funding Agency) before starting data gathering.

\section{Authors' Contributions}

R-MH drafted and wrote the manuscript.

\section{Acknowledgements}

The authors gratefully acknowledge all the members of KTP for their contributions to the KTP documentation and information used in this manuscript.

\section{Availability of Data and Materials}

Minutes of the meetings are not available for public. Report of the working groups is mentioned in the list of references: Opetus- ja kulttuuriministeriö. 2013. Liikuntatiedon saavutettavuuden kehittäminen. Liikuntatiedon saavutettavuuden kehittämishanke -työryhmä.

\section{Funding}

The research leading to these results within the REsearch into POlicy in Physical Activity (REPOPA), October 2011 to September 2016, has received funding by the EU Seventh Framework Program (FP7/2007-2013) [grant agreement no 281532]. This document reflects only the authors' views and neither the European Commission nor any person on its behalf is liable for any use that may be made of the information contained herein.

\section{Members of the REPOPA Consortium}

Coordinator: University of Southern Denmark (SDU): Arja R Aro, Maja Bertram (former Larsen), Mette W Jakobsen, Natasa Loncarevic, Gabriel Gulis, Thomas Skovgaard. Partners: Tilburg University (TiU): Ien AM van de Goor, Hilde Spitters, Marcel Quanjel, The Netherlands; Dutch Institute for Healthcare Improvement (CBO) - as 
of August 2012 replaced The Netherlands Institute for Health Promotion (NIGZ): Jan Jansen, Annemiek Dorgelo; The Finnish National Institute for Health and Welfare (THL): Riitta-Maija Hämäläinen, Tiia Villa, Timo Ståhl; Babes-Bolyai University (UBB): Razvan M Chereches, Diana Rus, Petru Sandu, Emanuela Oana Marton-Vasarhely; The Institute of Research on Population and Social Policies (IRPPS): Adriana Valente, Tommaso Castellani; The Institute of Clinical Physiology (IFC): Fabrizio Bianchi, Liliana Cori, The Italian National Research Council (CNR), Italy; School of Nursing, University of Ottawa (uOttawa): Nancy Edwards, Sarah Viehbeck, Susan Roelofs, Canada; Research Centre for Prevention and Health (RCPH), The Capital Region of Denmark: Torben Jørgensen, Charlotte Glümer, Cathrine Juel Lau, Denmark; Herefordshire Primary Care Trust until March 2013 (HPCT): Alison Talbot-Smith, Sarah Aitken, Clare Wichbold, Ahmed M Syed, Alison Merry, United Kingdom. www.repopa.eu.

\section{Competing Interests Statement}

The author declares that she has no competing interests.

\section{References}

Barwick, M. A., Schachter, H. M., Bennett, L. M., McGowan, J., Ly, M., Wilson, A., ... Manion, I. (2012). Knowledge translation efforts in child and youth mental health: A systematic review. J Evid Based Soc Work, 9(4), 369-95. https://doi.org/10.1080/15433714.2012.663667

Boyko, J.A., Lavis, J.N., Abelson, J., Dobbins, M., \& Carter, N. (2012). Deliberative dialogues as a mechanism for knowledge translation and exchange. Soc Sci Med., 75(11), 1938-45. https://doi.org/10.1016/j.socscimed.2012.06.016

Brownson, R.C., Royer, C., Ewing, R., McBride, T.D. (2005). Researchers and policymakers: travels in parallel universes. Am J Prev Med, 30, 164-172. https://doi.org/10.1016/j.amepre.2005.10.004.

Buse, K., Mays, N., \& Walt, G. (2012). Making Health Policy. Berkshire, England: Open University Press.

Canadian Institutes of Health Research. (2004).Innovation in action: knowledge translation strategy 2004-09. Ottawa: CIHR.

Clark, S., \& Weale, A. (2012). Social values in health priority setting: a conceptual framework. Journal of Health Organization and Management, 26(3),293-316. https://doi.org/10.1108/14777261211238954

El-Jardali F, Fadlallah R. (2015). A call for a backward design to knowledge translation. Int J Health Policy Manag, 4(1), 1-5. https://doi.org/10.15171/ijhpm.2015.10

El-Jardali, F., Jamal, D., Ataya, N., Jaafar, M., Raouf, S., Matta, C., Michael, S., \& Smith, C. (2011). Health policy and systems research in twelve Eastern Mediterranean countries: a stocktaking of production and gaps (20002008). Health Res Policy Syst, 9, 39. https://doi.org/10.1186/1478-4505-9-39

El-Jardali, F., Lavis, J.N., Ataya, N., Jamal, D., Ammar, W., \& Raouf, S. (2012). Use of health systems evidence by policymakers in eastern Mediterranean countries: views, practices, and contextual influences. BMC Health Serv Res, 12, 200. https://doi.org/10.1186/1472-6963-12-200

European Commission, Directorate-General for Research, Socio-economic Sciences and Humanities. (2010). Communicating research for evidence-based policymaking. A practical guide for researchers in socio-economic sciences and humanities. Luxembourg: Publications Office of the European Union.

Giles-Corti, B., Sallis, J.F., Sugiyama, T., Frank, L.D., Lowe, M., \& Owen, N. (2015). Translating active living research into policy and practice: One important pathway to chronic disease prevention. $J$ Public Health $P$. 36(2), 231-243. https://doi.org/10.1057/jphp.2014.53

Hallsworth, M. (2011). Policy-Making in the Real World. Political Insight, 2(1), 10-12. https://doi.org/10.1111/j.2041-9066.2011.00051.x

Hämäläinen, R-M., \& Villa, T. (2014). Terveyttä edistävän liikunnan politiikkatoimet ja tutkimustiedon käyttö (Role of use of research evidence in health enhancing physical activity policy making). Liikunta ja Tiede, 51(1), 36-43.

Haskell, W. L., Blair, S. N., \& Hill, J. O. (2009). Physical activity: Health outcomes and importance for public health policy. Preventive Medicine. 49, 280-282. https://doi.org/10.1016/j.ypmed.2009.05.002

Hawkes, S., Aulakh, B. K., Jadeja, N., Jimenez, M., Buse, K., Anwar, I., ... Whitworth, J. (2015). Strengthening capacity to apply health research evidence in policy making: experience from four countries. Health Policy Plan. Epub 2015 Apr 21. https://doi.org/10.1093/heapol/czv032 
Hunter, D. J. (2009). Relationship between evidence and policy: A case of evidence-based policy or policy-based evidence? Public Health, 123, 583-586.https://doi.org/10.1016/j.puhe.2009.07.01

Ilmakunnas, S., Junka, T., \& Uusitalo, R. (2008). Vaikuttavaa tutkimusta. Miten arviointitutkimus palvelee päätöksenteon tarpeita? Helsinki: Valtion taloudellinen tutkimuskeskus. VATT-julkaisuja 47. Helsinki: Nord Print Oy.

Kestilä, L., Mäki-Opas, T., Kunst, A.E., Borodulin, K., Rahkonen, O., \& Prättälä, R. (2014). Childhood Adversities and Socioeconomic Position as Predictors of Leisure-Time Physical Inactivity in Early Adulthood. Journal of Physical Activity and Health, 12(2), 193-9. https://doi.org/10.1123/jpah.2013-0245

LaRocca, R., Yost, J., Dobbins, M., Ciliska, D., \& Butt, M.(2012). The effectiveness of knowledge translation strategies used in public health: a systematic review. BMC Public Health, 12:751. https://doi.org/10.1186/1471-2458-12-75

Lavis, J. N., Robertson, D., Woodside, J., McLeod, C., \& Abelson, J., \& Knowledge Transfer Research Group. (2003). How can research organizations more effectively transfer research knowledge to decision makers? Millbank Q, 81(2), 221-48, 171-2.

Lavis, J. N. S., Boyko, J. A., Oxman, A. D., Lewin, S., \& Fretheim, A. (2009). SUPPORT Tools for evidenceinformed health policymaking (STP) 14: organising and using policy dialogues to support evidence-informed policymaking. Health Res Policy Syst, 7, S14. https://doi.org/10.1111/1468-0009.00005

Lee, I. M., Shiroma, E. J., Lobelo, F., Puska, P., Blair, S. N., \& Katzmarzyk, P. T. (2012). Effect of physical inactivity on major non-communicable diseases worldwide: an analysis of burden of disease and life expectancy. The Lancet, 380 (9838), 219-29. doi:10.1016/S0140-6736(12)61031-9

Malta, D. C., \& Barbosa da Silva, J.(2012). Policies to promote physical activity in Brazil. The Lancet, 380, 195-196. https://doi.org/10.1016/S0140-6736(12)61041-1

Ministry of Health and Long Term Care. (2008). Ontario Public Health Standards. Foundational Standard. Ministry of Health and Long Term Care, Ontario, Canada.

Moat, K. A., Lavis, J. N., \& Abelson, J. (2013). How context and issues influence the use of policy relevant research syntheses: a critical interpretive synthesis. Milbank $Q$, 91(3), 604-48. https://doi.org/10.1111/1468-0009.12026

Moat, K.A., Lavis, J.N., Clancy, S.J., El-Jardali, F., \& Pantoja, T. (2014). Evidence briefs and deliberative dialogues: perceptions and intent to act on what was learnt. Bull World Health Organ, 92, 20-28. https://doi.org/10.2471/BLT.12.116806

Ojajärvi, S., Valtonen, S., \& Pyykkönen, T. (2013). Liikuntalaiva tietomerellä - navigointia politiikan ja julkisuuden tuulissa. Liikuntatieteellisen Seuran Impulssi, 27. Tampere: Tammerprint Oy.

Opetus- ja kulttuuriministeriö. (2013). Liikuntatiedon saavutettavuuden kehittäminen. Liikuntatiedon saavutettavuuden kehittämishanke -työryhmä. Opetus- ja kulttuuriministeriön työryhmämuistioita ja selvityksiä 2013:4.

Opetusministeriö. (2006). Strategisen tiedolla johtamisen kehittäminen liikunnan valtionhallinnossa. Opetusministeriön työryhmämuistioita ja selvityksiä 2006:20.

Palinkas, L. A., Horwitz, S. M., Green, C. A., Wisdom, J. P., Duan, N., \& Hoagwood, K. (2015). Purposeful Sampling for Qualitative Data Collection and Analysis in Mixed Method Implementation Research. Adm Policy Ment Health, 42, 533-544. https://doi.org/10.1007/s10488-013-0528-y

Pratt, M., Perez, L. G., Goenka, S., Brownson, R. C., Bauman, A., Sarmiento, O.L., \& Hallal, P. C. (2015). Can population levels of physical activity be increased? Global evidence and experience. Progress in Cardiovascular Diseases, 57, 356-367. https://doi.org/10.1016/j.pcad.2014.09.002

Prime Minister's Office. Government Report on the Future: well-being through sustainable growth. Prime Minister's Office Publications 20/2013.

Proper, K. I., Singh, A. S., van Mechelen, W., \& Chinapaw, M. J. (2011). Sedentary behaviors and health outcomes among adults: a systematic review of prospective studies. Am J Prev Med. https://doi.org/10.1016/j.amepre.2010.10.015

Roskam, A. J. R., Kunst, A. E., Van Oyen, H., Demarest, S., Klumbiene, J., Regidor, E., ... \& additional participants to the study. (2009). Comparative appraisal of educational inequalities in overweight and obesity 
among adults in 19 European countries. International journal of epidemiology, 39(2), 392-404. https://doi.org/10.1093/ije/dyp329

Scott, S. D., Albrecht, L., O’Leary, K., Ball, G. D., Hartling, L., Hofmeyer, A., ... Dryden, D. M.(2012). Systematic review of knowledge translation strategies in the allied health professions. Implement Sci, 7(70). https://doi.org/ 10.1186/1748-5908-7-70

Smits, P.A., \& Denis, J-L. (2014). How research funding agencies support science integration into policy and practice: An international overview. Implementation Science, 9(28). https://doi.org/10.1186/1748-5908-9-28

Straus, S. E., Tetroe, J., \& Graham, I. (2009). Defining knowledge translation. CMAJ, 181, 165-8. https://doi.org/10.1503/cmaj.081229

Valtioneuvoston kanslia. (2011). Poliittisen päätöksenteon tietopohjan parantaminen - tavoitteet todeksi. Politiikkatoimien vaikuttavuusarvioinnin kehittämistyöryhmän raportti. Valtioneuvoston kanslian julkaisusarja 8/2011. Helsinki: Edita Oy.

Valtonen, S., \& Ojajärvi, S. (2013). Kohti liikuntatiedon tehokkaampaa hyödyntämistä. Liikuntatieteellinen seura and Valtion Liikuntaneuvosto. 2013:4.

Virtanen, P., Stenvall, J., \& Rannisto, P-H. (Eds.). (2015). Tiedolla johtaminen valtionhallinnossa. Tampere University Press.

Wallace, J., Byrne, C., \& Clarke, M. (2012). Making evidence more wanted: a systematic review of facilitators to enhance the uptake of evidence from systematic reviews and meta-analyses. Int J Evid Based Healthc, 10(4), 338-346. https://doi.org/10.1111/j.1744-1609.2012.00288

Wallace, J., Nwosu, B., \& Clarke, M. (2012). Barriers to the uptake of evidence from systematic reviews and meta-analyses: A systematic review of decision makers' perceptions. BMJ Open, 2, e001220. https://doi.org/10.1136/bmjopen-2012-001220

\section{Copyrights}

Copyright for this article is retained by the author(s), with first publication rights granted to the journal.

This is an open-access article distributed under the terms and conditions of the Creative Commons Attribution license (http://creativecommons.org/licenses/by/4.0/). 